\title{
Diagnosis and Management of Short Cervix in Singleton Pregnancies
}

\author{
Arnon Agmon, Ariel J, Igal Wolman \\ Ultrasound Unit in Obstetrics and Gynecology, Lis Maternity Hospital, Tel Aviv Medical Center, Sackler Faculty of Medicine,Tel Aviv \\ University, Tel Aviv, Israel
}

Correspondence: Arnon Agmon, Ultrasound Unit in Obstetrics and Gynecology, Lis Maternity Hospital, Tel Aviv Medical Center 6 Weizman St, Tel Aviv-64239, Israel, Phone: 972-3-6911669, Fax: 972-3-6911559, e-mail: arnon@ arnonagmon.com

\section{ABSTRACT}

Prevention of preterm labor will reduce perinatal mortality. Screening of cervical length by ultrasound should begin at 16 weeks by transvaginal ultrasound. If the cervical length is more than $35 \mathrm{~mm}$, the exam should be repeated every 2 to 3 weeks till 32 weeks. If the cervical length is between 25 and $35 \mathrm{~mm}$ the ultrasound screening should be done weekly or biweekly. Fetal fibronectin estimation should provide supplemental information. If the cervical length is less than $25 \mathrm{~mm}$ cervical cerclage should be performed if gestational age is less than 22 weeks. Progesterone therapy is preferred if the gestational age is more than 22 completed weeks.

Keywords: Preterm labor, PPROM, Ultrasound cervical length, Cervical cerclage, Progesterone therapy.

\section{INTRODUCTION}

Preterm delivery (PTD) is the leading cause of infant mortality. ${ }^{1}$ One in 10 pregnant women in the US will deliver prematurely, of whom $2 \%$ will deliver prior to completed 32 weeks of gestation. ${ }^{1}$ Between 60 and $80 \%$ of all nonanomalous infant deaths are attributed to PTD, and as many as $30 \%$ of infants born prior to the 31 st gestational week and $60 \%$ of infants born prior to the 26th gestational week will suffer some form of disability. ${ }^{1}$ Recent reports described an increase in the incidence of preterm births, resulting in growing pressure on health services and healthcare providers. ${ }^{2}$ The major causes of PTD are preterm labor (PTL), preterm rupture of membranes (PTROM), and multiple gestation pregnancies, accounting for as many as $80 \%$ of all cases. The causes for the other $\sim 20 \%$ PTD cases include maternal and fetal conditions, such as cervical incompetence, hypertension, infection, bleeding, and fetal growth restriction. PTD is also associated with socioeconomic and occupational factors, such as low socioeconomic status, pregnancy at early age, single women, depression, and deleterious working conditions. Despite the awareness of these associations, maternal risk scoring fails to detect up to $70 \%$ of infants who are delivered spontaneously before term. ${ }^{3}$

Cervical incompetence accounts for 8 to $9 \%$ of preterm deliveries. The diagnosis of incompetent cervix is based upon historical, clinical and sonographical findings. Clinical findings of premature cervical effacement or painless dilation of the

Date of Received: 23-08-10

Date of Acceptance: 16-09-10

Date of Publication: Jan. 2011 cervix, soft cervix on digital examination, or fetal membrane bulging are suggestive of incompetent cervix. Other clues of incompetent cervix include previous second trimester loss, preterm delivery, precipitated labors as well as cervical dilation before the onset of labor. Sonographic signs of cervical incompetence often present prior to clinical signs and include shortening of cervical length and funneling. ${ }^{4}$

\section{MEASUREMENT OF CERVICAL LENGTH BY ULTRASOUND}

Cervical length can be assessed manually or by ultrasound (US) examination. Manual examination of cervical length has high intraobserver variation ( $>50 \%$ ), is inaccurate when compared with US measurement, and has limited value in assessing the internal os. Unlike a digital examination, sonographic evaluation of the cervix allows the inspection of the internal os and proximal cervix. ${ }^{5}$ Adherence to the basic rules for cervical length measurement is essential. The maternal bladder should be emptied prior to the examination, which should be performed transvaginally. The vaginal probe should be inserted into the vaginal fornix and then withdrawn gently until no pressure is being applied to the cervix. The cervix should be observed for a few minutes after which pressure should be applied to the uterine fundus. Measurements should be made between the external os to the internal os along the cervical canal. If there is funneling, the measurement should be made until the point of funneling (Fig. 1).

\section{CAN WE PREDICT PRETERM DELIVERY?}

Predicting PTD delivery has proven to be elusive. PTD can occur in nulligravid women without any apparent risk factors 
as well as in asymptomatic women. Indeed, uterine contractions are a normal part of pregnancy, and they do not necessarily precede delivery. In fact, the condition resolves spontaneously in $50 \%$ of symptomatic gravid women hospitalized for preterm contractions and they go on to deliver at term. ${ }^{6}$

Currently employed methods for the prediction of PTD are fetal fibronectin and cervical length. Discovered in 1991, fibronectin was found to have a high sensitivity (93\%) and negative predictive value (99\%) for predicting PTD in symptomatic patients. However, fibronectin has low positive predictive value (30\% in most populations) and does not change the clinical management in most cases. ${ }^{7}$ It is reliable only when measured after 22 weeks of gestation. In addition, it may produce false results in the presence of semen, lubricants and other substances in the vagina. Furthermore, fibronectin is not accurate in predicting PTD in asymptomatic women. Nevertheless, it was found to increase the sensitivity of cervical length measurement when the cervix is less than $30 \mathrm{~mm}$ long. ${ }^{8}$ It has been suggested that fibronectin be measured simultaneously with ultrasonic cervical length in borderline situations (i.e. when the cervix is $20-30 \mathrm{~mm}$ long). ${ }^{9}$

Cervical length changes during pregnancy. The median is 35 to $40 \mathrm{~mm}$ at 24 to 28 weeks of gestation and 30 to $35 \mathrm{~mm}$ at 32 weeks' gestation. Between 22 to 30 weeks of gestation, the
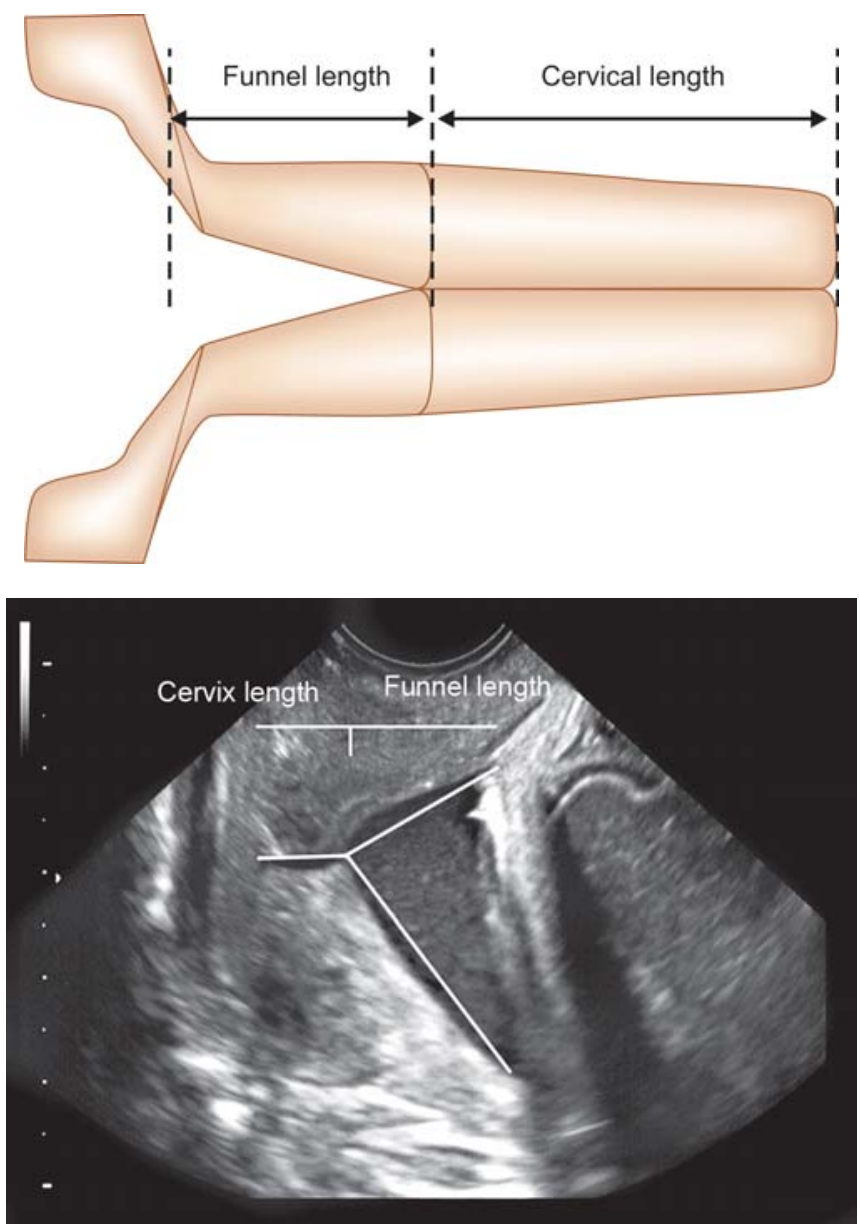

Fig. 1: Measurement of cervical length 10th percentile of cervical length is $25 \mathrm{~mm}$. Overall, a cervix shorter than $25 \mathrm{~mm}$ in length is abnormal. In a prospective multicenter study involving over 2500 women, Iams et $\mathrm{al}^{10}$ showed a correlation between cervical length measured at 24 weeks' gestation and PTD prior to 35 weeks' gestation. Those authors showed that the risk of PTD increases as cervical length shortens. Others have reported the same correlation. 5,11,12 The specificity of US is higher than fibronectin for measuring cervical length (40 vs 18\% respectively), while the sensitivity, negative and positive predictive values are similar. Heath et $\mathrm{al}^{13}$ reported that a cervix less than $15 \mathrm{~mm}$ in length is a strong predictor of PTD, and concluded that measurement of cervical length provides accurate prediction of risk for early PTD.

\section{Low-risk versus High-risk and Symptomatic versus Nonsymptomatic Women}

There is a general consensus that cervical length should not be applied as a screening tool in low-risk patients. ${ }^{14}$ Leitich et $\mathrm{al}^{15}$ reviewed 13 studies on the efficacy of US in predicting PTL in both symptomatic and asymptomatic women, and found US not to be efficacious for the latter. In their study on low-risk primigravid women, Iams and Goldenberg ${ }^{16}$ did not find cervical length at 22 to 24 weeks' gestation to be predictive of PTL in this population. The literature does, however, support the use of US for measuring the cervix in high-risk and symptomatic women. ${ }^{14}$ In a systematic review of the literature, Crane et $\mathrm{al}^{17}$ concluded that cervical length measured by transvaginal US in asymptomatic high-risk women can predict spontaneous PTL at less than 35 weeks. ${ }^{17}$ Owen et $\mathrm{al}^{18}$ showed that cervical length of less than $25 \mathrm{~mm}$ is predictive of PTD before 35 weeks' gestation in a group of women with singleton pregnancy and prior PTD (RR 3.3, 95\% CI 2.1-5.0). Tsoi et $\mathrm{al}^{19}$ examined 216 women at 24 to 36 weeks' gestation with a singleton pregnancy and painful contractions. After excluding women in active labor or ruptured membranes, over one-third (37\%) of the study women whose cervix was less than $15 \mathrm{~mm}$ long delivered within 7 days regardless of therapy. Only one out of 173 women whose cervix was $15 \mathrm{~mm}$ or more in length delivered within 7 days. Those authors concluded that sonographic measurement of cervical length helps distinguish between true and false labor in women with threatened PTD. In their review of the literature, Grimes-Dennis and Berghella concluded that cervical length is a predictor of PTD in all groups studied, symptomatic or not. They reported that using cervical length as a screening tool for prediction and prevention of PTL can significantly improve the health outcomes of pregnant patients and their babies. ${ }^{5}$

The issue of funneling (dilation of the internal cervical os and canal) is less clear. Several reports claimed that funneling of less than $25 \%$ of the closed cervix is not associated with PTD, while funneling of more than $25 \%$ predicts a higher risk for PTD. ${ }^{20}{ }^{21}$ Moreover, the combination of funneling and a short cervix is a more powerful predictor of PTD compared with a short cervix alone. ${ }^{20}$ It is unclear whether funneling in a 
cervix of normal length (more than $25 \mathrm{~mm}$ ) could serve as a predictor of PTD. ${ }^{22}$

Cervical length is the best currently available method for predicting PTD. The method of measuring is safe, reliable, well accepted and considered as being valid in all populations studied. A cervix less than $25 \mathrm{~mm}$ in length at 16 to 24 weeks' gestation is a reliable indicator of increased risk for PTD.

\section{HOW SHOULD WE MANAGE A SHORT CERVIX?}

Many measures have been proposed for the prevention of PTD, and they are mostly unsubstantiated. Cerclage for early intervention and progesterone for later intervention are the most prominent among them. Althuisius et $\mathrm{al}^{23}$ studied cerclage outcome in women with risk factors for PTD and/or symptoms of cervical incompetence, and a cervix less than $25 \mathrm{~mm}$ in length before 27 weeks of gestation. They found that therapeutic cerclage with bed rest reduces PTD before 34 weeks of gestation and reduces neonatal morbidity. Other investigators, however, did not observe those results. ${ }^{24,25}$ In their 2003 Cochrane review, Darkeley et $\mathrm{al}^{26}$ did not find cerclage to be useful in preventing second trimester loss or preterm birth (before 34 weeks) whether or not a short cervix had been diagnosed prior to the procedure. Cerclage has been associated with pyrexia, tocolysis use and hospital admissions. Berghella et $\mathrm{al}^{27}$ performed a meta-analysis of four randomized trials that examined whether cerclage, as opposed to bed rest, prevented PTD in women with a short cervix discovered by US during secondtrimester screening. Cerclage was associated with significantly fewer PTDs at less than 37 weeks (RR 0.84; CI 0.71-0.99), fewer PTDs at less than 35 weeks for women with previous second trimester PTD (RR 0.75; CI 0.58-0.97), and fewer PTDs for women with a cervix less than $25 \mathrm{~mm}$ in length. Screening for cervical length in women with prior second trimester PTD may alert the clinician to the women who are more likely to benefit from cerclage.

Recent years have witnessed a growing interest in progesterone as a promising agent in the management of imminent PTD. Progesterone was shown to block the activity of oxytocin on the myometrium, inhibit gap junction formation between muscle cells and inhibit smooth muscle contraction. ${ }^{28}$ In clinical studies, progesterone was found to be effective in preventing PTD and its complications in high-risk women, especially those who experienced PTD in the past. ${ }^{29,30}$ In 2006 Cochrane review, Dodd et $\mathrm{al}^{31}$ showed that women at risk for PTD who received intramuscular progesterone were less likely to deliver at less than 37 weeks. Their infants were less likely to be born at a birth weight of less than $2500 \mathrm{gm}$ and less likely to suffer from intraventricular hemorrhage. Dodd et $\mathrm{al}^{31}$ concluded that progesterone prolongs pregnancies in women at high risk, but those authors were unable to determine whether such prolongation is beneficial given the limited information on progesterone safety or its effectiveness when administered in the vaginal route. Fonseca et $\mathrm{al}^{32}$ studied over 400 women with midtrimester short cervix (less than $15 \mathrm{~mm}$ ) that had been found on routine scanning and randomized them to vaginal progesterone or bed rest. The women who received progesterone had significantly fewer deliveries at less than 34 weeks and did not suffer any significant side effects from the medication.

\section{CONCLUSIONS}

PTD is a serious condition with considerable impact on fetal mortality and morbidity. Managing the complications of PTD puts a major financial burden on community resources. Our recommendations for the management of PTD are as follows:

1. Women at high risk for PTD might benefit from screening of the cervical length between 16 and 24 weeks. If it measures more than $35 \mathrm{~mm}$, the exam should be repeated every 2 to 3 weeks until 32 weeks' gestation.

2. A cervical length of 35 to $25 \mathrm{~mm}$ should be managed with weekly or biweekly follow-up to monitor the length of the cervix over time.

3. Fibronectin testing can be given to provide supplemental information when cervical length is between 20 to $30 \mathrm{~mm}$ in examinations performed after 22 weeks' gestation.

4. If the cervical length is less than $25 \mathrm{~mm}$, the choice of therapy will depend on gestational age: Cerclage should be performed following exclusion of infection and PTROM at less than 22 completed weeks. If the cervical length is less than $25 \mathrm{~mm}$ at more than 22 completed weeks, intramuscular progesterone is the preferred therapy.

\section{REFERENCES}

1. Berkowitz GS, Papiernik E. Epidemiology of preterm birth. Epidemiol Rev 1993;15:414-43.

2. Green NS, Damus K, Simpson JL, Iams J, Reece EA, Hobel CJ, et al. March of Dimes Scientific Advisory Committee on prematurity. Research agenda for preterm birth: Recommendations from the March of Dimes. Am J Obstet Gynecol 2005;193:626-35.

3. Armson BA DL. Prediction of preterm birth in a population of Canadian women. Int J Gynecol Obstet 1994;46:9(Suppl 2).

4. Harger JH. Cerclage and cervical insufficiency: An evidencebased analysis. Obstet Gynecol 2002;100:1313-27.

5. Grimes-Dennis J, Berghella V. Cervical length and prediction of preterm delivery. Curr Opin Obstet Gynecol 2007;19:19195.

6. McPheeters ML, Miller WC, Hartmann KE, Savitz DA, Kaufman JS, Garrett JM, et al. The epidemiology of threatened preterm labor: A prospective cohort study. Am J Obstet Gynecol 2005;192:1325-29.

7. Lockwood CJ. Predicting premature delivery-no easy task. N Engl J Med 2002;346:282-84.

8. Gomez R, Romero R, Medina L Nien JK, Chaiworapongsa T, Carstens $\mathrm{M}$, et al. Cervicovaginal fibronectin improves the prediction of preterm delivery based on sonographic cervical length in patients with preterm uterine contractions and intact membranes. Am J Obstet Gynecol 2005;192:350-59.

9. Hincz P, Wilczynski J, Kozarzewski M, Szaflik K. Two-step test: The combined use of fetal fibronectin and sonographic examination of the uterine cervix for prediction of preterm delivery in symptomatic patients. Acta Obstet Gynecol Scand 2002;81:58-63.

10. Iams JD, Goldenberg RL, Meis PJ, Mercer BM, Moawad A, Das A, et al. The length of the cervix and the risk of spontaneous 
premature delivery. National Institute of Child Health and Human Development Maternal Fetal Medicine Unit Network. N Engl J Med 1996;334:567-72.

11. Romero R, Espinoza J, Erez O, Hassan S. The role of cervical cerclage in obstetric practice: Can the patient who could benefit from this procedure be identified? Am J Obstet Gynecol 2006;194:1-9.

12. Hassan SS, Romero R, Berry SM. Patients with an ultrasonographic cervical length $\leq 15 \mathrm{~mm}$ have nearly a $50 \%$ risk of early spontaneous preterm delivery. Am J Obstet Gynecol 2000;182:1458-67.

13. Heath VC, Southall TR, Souka AP, Elisseou A, Nicolaides KH. Cervical length at 23 weeks of gestation: Prediction of spontaneous preterm delivery. Ultrasound Obstet Gynecol 1998;12:312-17.

14. ACOG Practice Bulletin. Cervical insufficiency. Obstet Gynecol 2003;102:1091-99.

15. Leitich H, Brunbauer M, Kaider A, Egarter C, Husslein P. Cervical length and dilatation of the internal cervical os detected by vaginal ultrasonography as markers for preterm delivery: A systematic review. Am J Obstet Gynecol 1999;181:1465-72.

16. Iams JD, Goldenberg RL, Mercer BM. The preterm prediction study: Can low-risk women destined for spontaneous preterm birth be identified? Am J Obstet Gynecol 2001;184:652-55.

17. Crane JM, Hutchens D. Transvaginal sonographic measurement of cervical length to predict preterm birth in asymptomatic women at increased risk: A systematic review. Ultrasound Obstet Gynecol 2008;31:579-87.

18. Owen J, Yost N, Berghella V. Mid-trimester endovaginalsonography in women at high risk for spontaneous preterm birth. JAMA 2001;286:1340-48.

19. Tsoi E, Akmal S, Rane S, Otigbah C, Nicolaides KH. Ultrasound assessment of cervical length in threatened preterm labor. Ultrasound Obstet Gynecol 2003;21:552-55.

20. Rust OA, Atlas RO, Kimmel S, Roberts WE, Hess LW. Does the presence of a funnel increase the risk of adverse perinatal outcome in a patient with a short cervix? Am J Obstet Gynecol 2005;192:1060-66.

21. Guzman ER, Walters C, Ananth CV. A comparison of sonographic cervical parameters in predicting spontaneous preterm birth in high-risk singleton gestations. Ultrasound Obstet Gynecol 2001;18:204-10.

22. Berghella V. Does funneling increase the incidence of preterm birth in women with normal cervical length? Am J Obstet Gynecol 2005;193:s147.

23. Althuisius SM, Dekker GA, Hummel P, Bekedam DJ, van Geijn HP. Final results of the cervical incompetence prevention randomized cerclage trial (CIPRACT): Therapeutic cerclage with bed rest versus bed rest alone. Am J Obstet Gynecol 2001;185:1106-12.

24. Berghella V, Odibo AO, Tolosa JE. Cerclage for prevention of preterm birth in women with a short cervix found on transvaginal ultrasound examination: A randomized trial. Am J Obstet Gynecol 2004;191:1311-17.

25. To MS, Alfirevic Z, Heath VC. Cervical cerclage for prevention of preterm delivery in women with short cervix: Randomised controlled trial. Lancet 2004;363:1849-53.

26. Drakeley AJ, Roberts D, Alfirevic Z. Cervical stitch (cerclage) for preventing pregnancy loss in women. Cochrane Database Syst Rev 2003;CD003253.

27. Berghella V, Odibo AO, To MS, Rust OA, Althuisius SM. Cerclage for short cervix on ultrasonography: Meta-analysis of trials using individual patient-level data. Obstet Gynecol 2005;106:181-89.

28. Zakar T, Hertelendy F. Progesterone withdrawal: Key to parturition. Am J Obstet Gynecol 2007;196:289-96.

29. Meis PJ, Klebanoff M, Thom E. Prevention of recurrent preterm delivery by 17 alpha-hydroxyprogesterone caproate. N Engl J Med 2003;348:2379-85.

30. Spong CY, Meis PJ, Thom EA. Progesterone for prevention of recurrent preterm birth: Impact of gestational age at previous delivery. Am J Obstet Gynecol 2005;193:1127-31.

31. Dodd JM, Flenady V, Cincotta R, Crowther CA. Prenatal administration of progesterone for preventing preterm birth. Cochrane Database Syst Rev 2006;CD004947.

32. da Fonseca EB, Bittar RE, Carvalho MH, Zugaib M. Prophylactic administration of progesterone by vaginal suppository to reduce the incidence of spontaneous preterm birth in women at increased risk: A randomized placebo-controlled double-blind study. Am J Obstet Gynecol 2003;188:419-24. 